Devinsky O, Verducci C, Thiele EA et al. (2018) Open-label use of highly purified CBD (Epidiolex®) in patients with $\mathrm{CDKL}_{5}$ deficiency disorder and Aicardi, Dupi5q, and Doose syndromes. Epilepsy \& Behavior 2018;86:131-137.

Farkas V, Steinborn B, Flamini JR et al. (20I9) Efficacy and tolerability of adjunctive lacosamide in pediatric patients with focal seizures. Neurology 2019;93:e1212-e1226.

Franco V, Perucca E (20I9) Pharmacological and therapeutic properties of cannabidiol for epilepsy. Drugs 2019;79:1435-1454.

French JA, Krauss GL, Wechsler RT et al. (2015) Perampanel for tonic-clonic seizures in idiopathic generalized epilepsy: A randomized trial. Neurology 2015;85:950-957. Multidisciplinaire richtlijn Dravetsyndroom Vereniging Klinische Genetica Nederland. www.Richtlijnendatabase. nl 2019.
Serafini A, Gerard E, Genton P et al. (20rg) Treatment of juvenile myoclonic epilepsy in patients of child-bearing potential. CNS Drugs 2019;33:195-208.

Strzelczyk A, Kay L, Bauer S et al. (2018) Use of brivaracetam in genetic generalized epilepsies and for acute, intravenous treatment of absence status epilepticus. Epilepsia 2018;59:1549-1556.

Suljic EM, Mehicevic A, Mahmutbegovic N (2018). Effect of long-term carbamazepine therapy on bone health. Med Arch 2018;72:262-266.

Villanueva V, Montoya J, Castillo A et al. (2018) Perampanel in routine clinical use in idiopathic generalized epilepsy: The I2 month GENERAL study. Epilepsia 2018;59:17401752.

Door: Eline van Hugte ${ }^{\mathrm{I}, 2,3}$ (elinevanhugte@radboudumc.nl), moleculaire neurofysiologie; Judith Verhoeven ${ }^{\mathrm{I}}$, kinderneurologie; Jurgen Schelhaas ${ }^{4}$, neurologie; Jason Keller², 3, moleculaire neurofysiologie; Elly Lewerissa ${ }^{2}$, 3, moleculaire neurofysiologie; Hans van Bokhoven 2, 3, moleculaire neurogenetica; Nael Nadif Kasri², 3, moleculaire neurofysiologie; Marian Majoie ${ }^{\mathrm{I}, 5}$, neurologie.

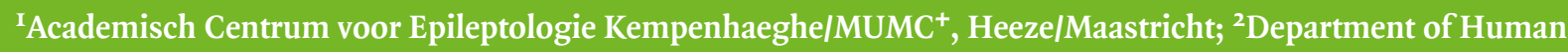
Genetics, Radboudumc, Nijmegen; ${ }^{3}$ Donders Institute for Brain, Cognition and Behaviour, Centre for Neuroscience, Radboud Universiteit Nijmegen; 4Stichting Epilepsie Instellingen Nederland (SEIN), Zwolle; 5 School of Mental Health and Neuroscience en School of Health Professions Education, Maastricht Universitair Medisch Centrum $\left(\mathrm{MUMC}^{+}\right)$

\title{
De pluripotente stamceltech- niek: de mogelijkheid om patiënt-eigen neuronen te bestuderen in het lab
}

In steeds meer onderzoeken naar neuronale ontwikkelingsstoornissen wordt gebruik gemaakt van humaan geïnduceerde pluripotente stamcellen. Deze techniek maakt het mogelijk om vanuit somatische cellen (zoals bloed- en huidcellen) stamcellen te verkrijgen die gedifferentieerd kunnen worden naar patiënt-eigen neuronale cellen. Naast het bestuderen van ziektemechanismes lenen deze neuronale cellen zich ook voor het testen van medicijnen op een patiëntspecifieke manier.

Wat is de toepasbaarheid van neuronen afkomstig uit humaan geïnduceerde pluripotente stamcellen (hIPSCs) voor onderzoek naar neuronale ontwikkelingsstoornissen, zoals epileptische encephalopathieën (EEE)? De EEE behoren tot een heterogene groep van moeilijk behandelbare epilepsieën die vaak voor het eerste levensjaar tot uiting komen. Er treden verschillende soorten aanvallen op, maar ook als er geen aanvallen zijn werken de hersenen niet goed, hetgeen een negatieve invloed heeft op de ontwikkeling van het kind. EEE kunnen ontstaan door verschillende oorzaken, maar worden symptomatisch gekenmerkt door een medicatieresistente epilepsie. Het voortbestaan van de epileptische activiteit draagt bij aan de cognitieve achteruitgang en gedragsstoornissen en 
vormt een bedreiging voor de ontwikkeling van het kind. Daarnaast kunnen EEE gepaard gaan met bewegingsstoornissen, autisme spectrum-stoornissen en ADHD. Het is daarom van cruciaal belang om de aanvallen zo snel en effectief mogelijk onder controle te krijgen (McTague et al., 20I6).

De laatste jaren zijn verschillende genetische mutaties geidentificeerd die geassocieerd worden met EEE. Desondanks blijft de kennis achter over hoe deze mutaties leiden tot epilepsie en cognitieve comorbiditeit. Daarnaast zijn patiënten met EEE met dezelfde genmutatie vaak klinisch heterogeen. Het is vanwege deze heterogeniteit voor de clinicus lastig om het aanvalsverloop door de jaren heen in te schatten. De clinicus zal de medicatiekeuze in eerste instantie baseren op algemene klinische richtlijnen die uitgaan van aanvalstype, epilepsietype en eventueel syndroomdiagnose. In vooralsnog vrij uitzonderlijke situaties (zoals bijvoorbeeld bij patiënten met een SCNIA-mutatie) zal ook de genmutatie worden meegewogen. Verschillende medi- camenten kunnen verschillende effecten hebben op het type en de ernst van de aanval, maar deze zijn niet patiëntspecifiek. Vaak worden dus verschillende anti-epileptica uitgeprobeerd waarbij de kans bestaat dat deze onvoldoende, niet of zelfs averechts werken. Hierdoor blijft medicatiekeuze vaak een weloverwogen trial and error-strategie. Dit leidt tot frustratie bij zowel arts, ouders als patiënt, maar bovendien tot tijdsverlies, terwijl het juist voor de ontwikkeling van het kind zo belangrijk is om de aanvallen tijdig onder controle te krijgen (McTague et al., 20r6). Hoewel er voor patiënten behorend tot de populatie van EEE heldere behandelrichtlijnen bestaan (NICE, 20I2) ontbreekt er een patiënt-specifieke gouden standaard. De ontwikkeling van hIPSCs kan een brug slaan naar het patiënt-specifiek testen van anti-epileptica buiten de patiënt om. Door verschillende genen (Oct4, cMyc, $\mathrm{Klf}_{3} / 4$, Sox2) tot expressie te brengen kunnen somatische cellen van patiënten tot hIPSCs geherprogrammeerd worden (Takahashi et al., 2007). De stamcellen kunnen oneindig

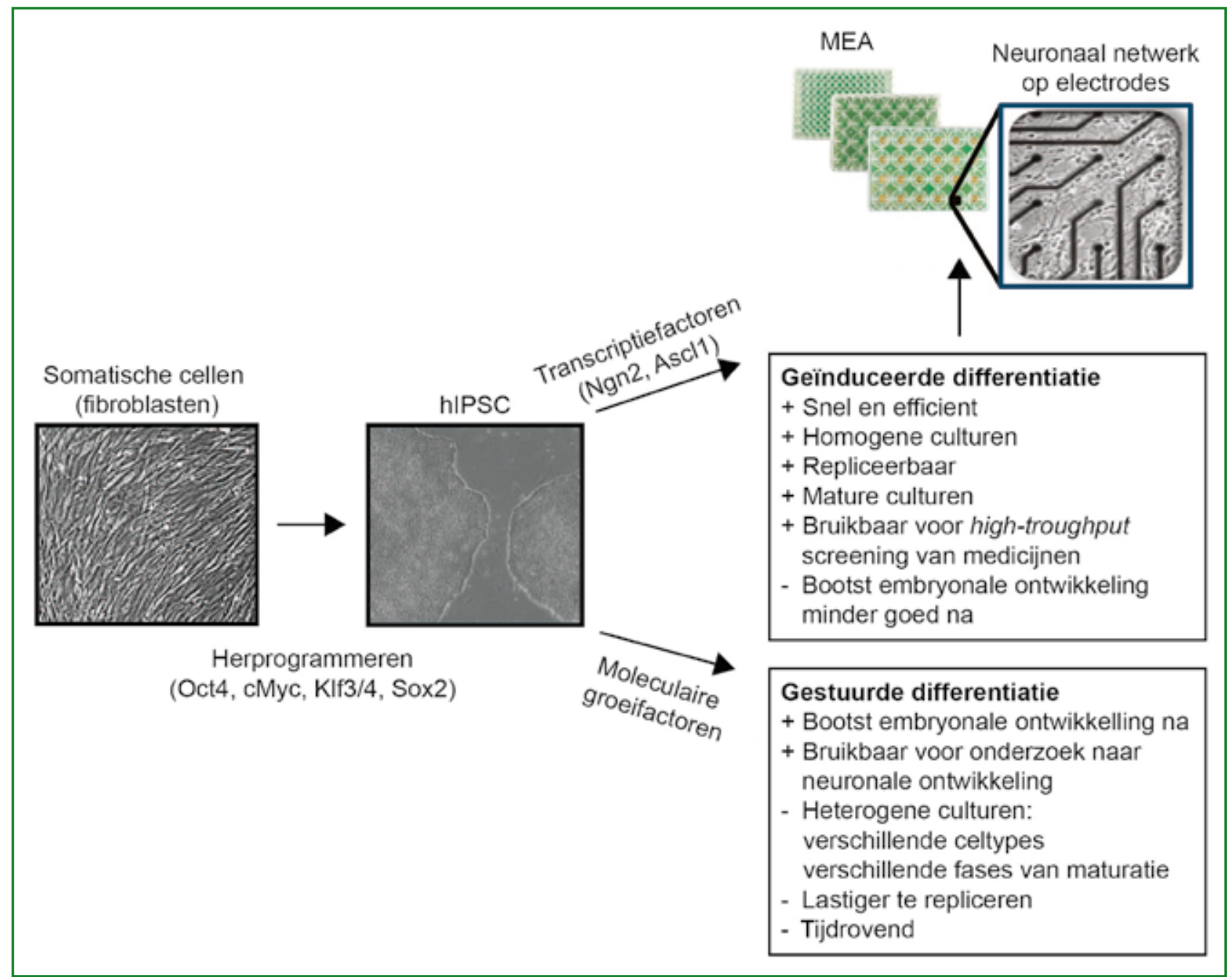

Figuur 1 Somatische patiënt-eigen cellen, in dit voorbeeld fibroblasten, worden met behulp van de expressie van vier genen (Oct4, cMyc, $\mathrm{Klf}_{3} / 4$ en Sox2) geherprogrammeerd tot stamcellen. Deze stamcellen kunnen op twee manieren gedifferentieerd worden tot neuronale netwerken, afhankelijk van het einddoel en de afweging van de voor- en nadelen van elke techniek. Vervolgens kunnen de neuronale netwerken uitrijpen op een MEA, een celkweekplaat met elektrodes op de bodem, die de activiteit van het neuronale netwerk kunnen meten. MEAs bestaan uit 96 (bovenste MEA) of 24 (onderste MEA) holtes. Zo kunnen 96 tot 24 neuronale netwerken tegelijkertijd worden gescreend. 
worden gekweekt en vormen een onuitputtelijke bron van patiënt-specifieke cellen, zodat er slechts eenmaal materiaalafname nodig is. In principe kunnen alle somatische cellen geherprogrammeerd worden, maar vooralsnog hebben fibroblasten vanuit een huidbiopt, bloedcellen of keratinocyten uit haarwortels de voorkeur vanwege praktische overwegingen. Doordat er met patiënt-eigen materiaal gewerkt wordt dragen de uiteindelijke hIPSCs exact dezelfde mutatie(s) en genetische achtergrond als de patiënt. De hIPSCs kunnen vervolgens naar neuronen worden gedifferentieerd.

Generatie van een patiënt-specifielk neuronaal netwerk De differentiatie van hIPSCs naar neuronale celtypes biedt perspectief voor onderzoek naar onderliggende mechanismen in de ontwikkeling van EEE. Inmiddels zijn er technieken waarmee de verschillende neuronale celtypes die een rol spelen bij epilepsie gedifferentieerd kunnen worden. Sommige technieken maken gebruik van moleculaire groeifactoren die ten grondslag liggen aan de embryonale hersenontwikkeling om een neuronaal netwerk in vitro te kweken. De gehele procedure voor de pluripotente stamceltechniek is schematisch weergegeven in figuur I. Het voordeel van dit soort gestuurde differentiatietechnieken is dat ze de neuronale ontwikkeling in vivo nabootsen. Dit maakt deze techniek bruikbaar voor onderzoek naar de onderliggende mechanismes die leiden tot het ontstaan van epilepsie. Een nadeel is dat deze techniek kan resulteren in heterogene neuronale netwerken, met een mix van verschillende celtypes in verschillende fases van maturatie die lastig te repliceren is. Daarnaast zijn deze technieken vaak tijdrovend. Dit maakt dit type techniek minder geschikt voor het testen van medicijnen.

Een andere manier om neuronale netwerken te kweken vanuit hIPSCs is door de cellen te differentiëren via geforceerde expressie van neuronale transcriptiefactoren. Transcriptiefactoren zijn eiwitten die ervoor zorgen dat genen 'aan' of 'uit' gezet worden. Transcriptiefactoren zoals NGN2 of ASCLI reguleren genen die belangrijk zijn voor de neuronale ontwikkeling. Met behulp van een virus kunnen NGN2 of ASCLI in hIPSCs tot expressie gebracht worden en differentiëren de hIPSCs tot respectievelijk excitatoire of inhibitoire neuronen (Yang et al., 2017; Zhang et al., 2013). Door deze excitatoire en inhibitoire neuronen samen in vitro te laten groeien vormen ze een functioneel, patiënt-eigen neuronaal netwerk. Ondanks het feit dat deze methode de embryonale hersenontwikkeling minder goed benadert, zijn de voordelen dat de neuronale netwerken homogeen zijn, snel kunnen worden gemaakt en kunnen worden gerepliceerd. Dit maakt neuronale netwerken van dit type uitermate geschikt voor het snel screenen van medicijnen, ook wel high-throughput screening genoemd.

\section{Het testen van medicijnen}

Patiënt-specifieke, functioneel actieve neuronale netwerken kunnen uitgroeien op petrischalen met electroden op de bodem, ook wel micro electrode arrays (MEAs) genoemd. Deze MEAs meten de activiteit van de neuronen continu en kunnen zo ingezet worden voor het testen van antiepileptica. Daarnaast bestaan MEAs uit platen van 24 tot 96 holtes, waarmee dus 24 tot 96 testen op neuronale netwerken tegelijkertijd kunnen worden gedaan (figuur I). Dit maakt ze uitermate geschikt voor high throughput screening. Parameters die uitgelezen kunnen worden van het neuronale netwerk zijn afzonderlijke actiepotentialen (spikes), opeenvolgende actiepotentialen (bursts) en netwerkactiviteit (network bursts) (Frega et al., 2017). De combinatie van deze parameters geeft een unieke, patiënt-specifieke netwerk-vingerafdruk. Deze unieke vingerafdruk, samen met het type mutatie en de genetische achtergrond van de patiënt, kan bijdragen tot het bepalen van de respons van individuele patiënten op anti-epileptica.

Voordat patiënt-eigen neuronale netwerken prospectief gebruikt kunnen worden voor gepersonaliseerde medicatie in de klinische praktijk, zal de techniek eerst gevalideerd worden. Hierbij wordt gebruik gemaakt van neuronale netwerken van patiënten met een goed gedocumenteerde respons op anti-epileptica, waarvan bekend is welk medicijn of combinatie van medicijnen goed werkt, of juist averechts werkt. Als de respons van het patiënt-eigen netwerk in vitro correleert met de respons van de patiënt op dezelfde medicijnen, kunnen neuronale netwerken op MEAs gebruikt worden voor effectievere en gerichtere therapeutische interventies.

\section{Tot slot}

De hIPSC-techniek biedt een robuust platform om neuronale netwerken en ziektemechanismes van patiënten met EEE te onderzoeken. Daarnaast is het mogelijk om deze neuronale netwerken te gebruiken om op een patiëntspecifieke manier medicijnen te testen. Er is echter nog extra onderzoek nodig voordat de neuronale netwerken daadwerkelijk in de klinische praktijk gebruikt kunnen worden als een medicatie-predictiemodel. De ontwikkelde technologie is echter veelbelovend en patiënt-eigen neuronale netwerken zullen zeker een belangrijke bijdrage leveren aan het begrijpen van epilepsie en van de neuronale ontwikkeling in het algemeen.

\section{Referenties}

Frega M, van Gestel SH, Linda K et al. (2017) Rapid neuronal differentiation of induced pluripotent stem cells for measuring network activity on micro-electrode arrays. Journal of visualized experiments: JoVE(IIg). McTague A, Howell KB, Cross JH et al. (20I6) The genetic landscape of the epileptic encephalopathies of infancy 
and childhood. The Lancet Neurology, 15(3), 304-316.

NICE (2012) Epilepsies: diagnosis and management

(Clinical guideline [CGI37]). Retrieved 04-09-2019, from

National Institute of Health and Care Excellence (NICE)

Takahashi K, Tanabe K, Ohnuki M et al. (2007) Induction

of pluripotent stem cells from adult human fibroblasts

by defined factors. Cell, 131(5), 86I-872.
Yang N, Chanda S, Marro S et al. (20I7) Generation of pure GABAergic neurons by transcription factor

programming. Nature methods, 14(6), 62I.

Zhang Y, Pak C, Han Y et al. (2013) Rapid single-step induction of functional neurons from human pluripotent stem cells. Neuron, 78(5), 785-798.

\section{Dravetsyndroom: cardiale comorbiditeit en plotse dood}

Op 28 augustus 2019 verdedigde Sharon Shmuely haar proefschrift getiteld 'The Heart of Epilepsy: Cardiac Comorbidity and Sudden Death' aan het University College London ${ }^{I}$. Ze toont aan dat cardiale comorbiditeit bij epilepsie vele oorzaken kent en dat het een belangrijke impact heeft op mortaliteit. Shmuely volgde een groot Dravet-cohort met langdurige ECG-metingen; ze vond geen ernstige ritmestoornissen maar wel een verhoogde prevalentie van ictale QTc-verlenging.

Kinderen met het Dravetsyndroom hebben een sterk verhoogd risico op SUDEP (Sudden Unexpected Death in Epilepsy). Er wordt gedacht dat ictale ritmestoornissen hierbij een rol spelen omdat (I) de erfelijke afwijking bij het Dravetsyndroom (SCNIA) ook tot expressie komt in het hart en (2) muizen met deze afwijking overlijden aan ictale ritmestoornissen. Er is echter nog geen klinisch onderzoek gedaan naar de effecten van aanvallen op het hart bij het Dravetsyndroom. Shmuely richtte haar onderzoek daarom op twee pijlers: het beter begrijpen van de cardiale comorbiditeit bij epilepsie en de rol van het hart bij SUDEP in relatie met het Dravetsyndroom.

\section{Cardiale comorbiditeit bij epilepsie}

Het proefschrift begint met een systematisch overzicht van de relatie tussen epilepsie en het hart (Shmuely \& Thijs, 20I9). Shmuely bespreekt alle mogelijke associaties aan de hand van comorbiditeit (Keezer et al., 20I6): causaal (bijvoorbeeld epileptische aanvallen die ritmestoornissen veroorzaken of vice versa), gedeelde risicofactoren (bijvoorbeeld ionkanaal-mutaties die de vatbaarheid voor epilepsie en ritmestoornissen verhogen) of associaties die het gevolg zijn van de aanvallen of de behandeling van epilepsie (bijvoorbeeld ritmestoornissen door anti-epileptica). Voor de associatie tussen de ionkanaalmutaties en
SUDEP geldt dat de beschrijvingen nog te veel berusten op anekdotische beschrijvingen.

\section{Vroegtijdig overlijden door SUDEP}

Omdat de literatuur over de mortaliteit bij het Dravetsyndroom nogal fragmentarisch is, heeft Shmuely een scoping review geschreven (Shmuely et al., 20I6a). Er werden 676 artikelen en 86 abstracts beoordeeld, waaruit in totaal 177 overlijdens geselecteerd werden. SUDEP bleek de belangrijkste doodsoorzaak (49\%) gevolgd door status epilepticus (32\%). De meeste overlijdens (73\%) traden op voor het tiende levensjaar. Dit contrasteert sterk met de SUDEPgegevens uit de algemene epilepsiepopulaties (Harden et al., 2017). De resultaten bieden houvast bij de counseling, maar laten ook zien dat er een noodzaak is voor onderzoek naar het verloop bij het Dravetsyndroom van grotere prospectieve cohorten.

\section{Valker QTc-verlenging}

In een prospectief multicenter onderzoek bekeek Shmuely de prevalentie van ictale ritmestoornissen bij het Dravetsyndroom. Met geavanceerde T-shirts met textiel-elektroden (3-kanaals ECG en accelerometrie) verrichtte zij langdurige metingen thuis (2o dagen) bij een groep van 59 patiënten van SEIN, Kempenhaeghe, Universitätsklinikum 